\title{
A Brief Analysis on the Problems and Propositions of Yunnan Culture Export to South and Southeast Asia
}

\author{
Bei Wu* \\ School of International Languages \& Cultures \\ Yunnan University of Finance \& Economics \\ Kunming, China \\ 16501955@qq.com
}

Chao Chen

\author{
School of Economics and Management \\ Yunnan Civil Construction Institute \\ Kunming, China \\ 870354424@qq.com
}

\section{Liang Ren}

Graduate student at Yunnan Minzu University

Kunming, China

734578935@qq.com

\begin{abstract}
In the context of "Belt and Road" Initiative, Yunnan culture actively seeks to develop towards South and Southeast Asia. The paper analyzes the existing problems of Yunnan culture at present, attempting to bring up new thoughts for the development of Yunnan culture, and to create more development opportunities.
\end{abstract}

Keywords-B\&R; Yunnan culture; expore; South and Southeast Asia

\section{INTRODUCTION}

Since China's reform and opening up, Yunnan has achieved some success in terms of culture export, but still being in the primary stage. For a long time, there exist various kinds of problems in Yunnan culture's export. These problems are realistic obstacles impeding the increase of Yunnan cultural soft power, directly or indirectly hindering the development pace of Yunnan's culture export, and restricting the development of foreign cultural trade. However, one of the goals of The Plan on Reinvigoration of the Cultural Industry is to further enlarge the export of cultural products and services [17]. In the context of "Belt and Road" Initiative, the paper would give new thoughts on how to develop Yunnan culture.

\section{LITERATURE REVIEW}

Opening-up and Cooperation between Yunnan and South Asian countries in Recent Years" in 2015 sets the reinforcement of educational cooperation and cultural communication as one of its priorities [13]. Jie Yang (2008) [5] believes that apart from economic and trade cooperation we should actively expand the cooperation domain with southern Asian countries in such as education, environmental protection, and cultural exchange, etc. Zhi Liu (1998) [1] thinks that Yunnan should exploit its advantages in ethnic cultural domain and enlarge the economic and cultural cooperation with southeastern Asian countries to promote Yunnan's economy. Based on the study of existing literature on Yunnan culture development, it is found that most of them focus on its

\footnotetext{
* Corresponding author
}

advantages; however, there is a blank in the deeper analysis of the problems of Yunnan culture export. It is hoped that this paper would contribute to facilitating Yunnan culture in South and Southeast Asia for the B\&R Initiative.

\section{PROBLEMS}

\section{A. The Lack of Ideal and Means to Export Yunnan Culture}

In recent years, Yunnan has extensively carried out activities with South and Southeast Asian areas, such as holding economic and cultural forum, hosting China-South Asia Expo, educating foreign students, promoting Mandarin Chinese, conducting exchange of visits between art teams, carrying out cultural exchanges at all levels, conducting news interaction and so on, thus forming a good trend for Yunnan culture export. However, there is a greater room for the improvement of mode innovation, channel innovation, and charm upgrade of cultural output based on a deep understanding of cultural characteristics of South and Southeast Asia. From the perspective of history and reality, South and Southeast Asian countries have their own complete and powerful ethnic and religious culture system. In view of economic exchanges and cultural experience needs, it is not possible for them to accept Chinese culture in large scale and deep level, especially to accept baptism of nondescript Yunnan ethnic culture. Therefore, when developing strategy for Yunnan culture to export, we cannot just emphasize the unilateral needs and idealized positioning of content and form. Considering the decline of Yunnan's own ethnic culture and not being in the core area of the Sinic culture, Yunnan needs to make active adjustment according to the changing modern culture but not to completely export the culture of ethnic minorities or traditional Confucianism culture as the leading culture to South and Southeast Asia. At present, Yunnan has explicit short board in cultivating the concept to develop modern cultural industry. In detail, there is no APP software developer that can integrate all the rich tourism resources in Yunnan province; All levels of governments in Yunnan province have not built powerful public service network and 
WeChat platform towards South and Southeast Asia, although these government bodies do emphasize the importance of constructing cultural exchange platform towards South and Southeast Asia; what's more, Yunnan is also lacking in systematic research on and planning for big data development or supply towards South and Southeast Asia.

\section{B. Competition for Yunnan in Deep Development and Utilization of Cultural Resources}

Yunnan and South and Southeast Asia are areas where cultural diversity is better preserved. There are more frequent cultural exchange and intensive integration in this region. The rich cultural resources and deep cultural roots have become the most significant features of this region. However, Yunnan has limited ability in deeply developing and utilizing cultural resources, and finds it difficult to gain a competitive advantage in the field of cultural product development. As for cultural resources, Yunnan culture does not have corresponding emotional appeal to South and Southeast Asia, although many ethnic minorities in Yunnan have the same source and common customs with people in South and Southeast Asia in the aspect of culture; moreover, the ethnic culture is interwoven and superimposed with Sinic culture, Western culture, and a lot of cultural resources can be exploited. On the one hand, the Yunnan people are indifferent to and even are not acquainted with their own traditional culture, thus some excellent cultural concepts remain idle resulting in the loss or death of a large number of ethnic cultural customs. On the other hand, the developed regions have strengthened the development and utilization of Yunnan's excellent traditional cultural resources by virtue of their advantages in concept, science and technology, and organizational operation, which has led to the new development of modern cultural industry combined with Yunnan cultural elements. For example, Tian Zhuangzhuang, a filmmaker from Beijing, once made a documentary called $\mathrm{De} \mathrm{La} \mathrm{Mu}$ in Yunnan province winning international prestige [12]; a fashion movie called Breakup Buddies reflecting inns of local lifestyle in Dali; American Middlebury College has conducted cultural programs such as cultural experience project by making use of Yunnan's ethnic cultural resources. All those work or projects led by the developed regions actively draws cultural nourishment from Yunnan's ethnic culture and modern culture. On the background of Yunnan traditional caravan culture, modern culture and traditional ethnic culture, the above cultural development activities are full of Yunnan cultural elements from interpretation of lifestyle, application of scenes and costumes to expression of thoughts and ideas. However, none of these above development behaviors belong to achievements of Yunnan's cultural enterprises, for Yunnan's insufficient ability of cultural development and utilization restricts creation of high-level cultural products. It can be seen that the lack of competent cultural enterprises has become the biggest bottleneck of Yunnan's development and utilization of their own cultural resources. In fact, many of the traditional and modern Yunnan cultural resources neglected by the Yunnan people are becoming the treasure competed for by the culturally developed areas and becoming the source of the latter's cultural innovation and have brought the developed areas good economic and social benefits [11]. Many of high- end cultural marketing products featured by Yunnan cultural characteristics have become strong competitors of local cultural products in Yunnan after getting the second creation and modern "decoration".

\section{The Lack of Content and Spiritual Value in Exporting Yunnan Culture}

In recent years, Yunnan has spared no effort to expand the cultural content to export in South and Southeast Asia. With the respect of foreign cultural exchange, Yunnan has planned and organized the "Experience China in Myanmar" series activities; in cooperation with Laos, a large-scale Chinese Spring Festival party in Laos was held. All of the above activities help to enhance cultural exchanges and promote friendships with related countries. As for international cultural communication, Yunnan has established special news column Beautiful Yunnan in the media of South and Southeast Asia; Yunnan has founded series publicity magazines in Southeastern Asian languages, such as Mekong River in Thai, Jixiang in Burmese, Zhanba in Lao, Khmer in Cambodia [15]; Yunnan also conducted cultural communication based on carriers including festival activities, newspapers, press and so on [10]. In terms of foreign cultural trades, Yunnan has made and fulfilled a three-year action plan for cultural industry export. At the same time, the amount of processing and exporting of folk crafts and gems has increased. But these exported cultural products cannot fully embody Yunnan modern culture's connotation. First, the exported Yunnan culture overemphasizes nationality but does not fully embody modern spirit. In the process of foreign cultural communication, Yunnan modern culture gets "aphasia" at the core value level because of loose combination of traditional culture and modern culture. Secondly, exported Yunnan culture does not highlight the deep charm of itself. The core charm of any culture generally depends on the ideology and value. Successful cultural communication is not only satisfied with the form of popular culture, but also pays more attention to the spread of ideas which means that popular culture is also given the rich ideological connotation, and increases the identification of ideology. For a long time, the United States has promoted and expressed its ideological culture by film and news, thus achieving a global cultural supremacy [2]. In recent years, although the forms of exported Yunnan culture are diversified, the content is not deeply exploited and the expression of core cultural value is deficient. In addition, the status of Yunnan culture export is that people regard Yunnan culture as ethnic and folk culture, such as ethnic festivals, ethnic crafts, dance, folk songs, folk art, etc. Even core news content such as news comments is less involved in foreign communication news. This kind of foreign communication news does not reflect the thought altitude of contemporary Yunnan culture from the perspective of cultural core values. Thirdly, international adaptability of exported Yunnan culture is not good. That is, the cultural contents selected lack fashion and timeliness; the cultural communication does not take multilevel international demands, changing cultural values and changing cultural interests into account. All these factors lead to poor communication effects of Yunnan culture in exporting to South and Southeast Asia mainstream society, especially in the upper classes. For example, the magazine Mekong River in 
Thai founded by Yunnan has limited recognition and influence in the mainstream society of Thailand. The localization of the television programme mainly meets the needs of small-group

\section{PROPOSITIONS}

In the process of exporting the modern culture with Yunnan characteristics, Yunnan needs to change the traditional concept of communication, which means, in the development of TV, newspapers and official websites towards South and Southeast Asia, we should also strengthen the construction of new cultural communication channels and the construction of informationalized culture carriers. From the perspective of development trend of culture digitalization, informatization and internationalization, these emerging communication means, communicative approaches and information processing platforms are not only the great tools to promote the largescale output of modern culture, but also reflect the characteristics of modern culture. In the current conditions of "Belt and Road" Initiative, Yunnan should get involved in the open, inclusive, fashionable and diverse modern cultural environment with a new gesture, actively export the new era of Yunnan modern cultural values, and set up a modern, open and fashionable image to South and Southeast Asian countries [3].

In the process of exporting Yunnan culture, we should pay attention to distinguishing the development and dissemination of cultural resources carried out by different subjects. The successful output of "Yunnan culture" in Beijing or Los Angeles is not necessarily equal to the successful promotion of the real "Yunnan culture". We have reason to believe that in the informationalized, highly developed market-oriented modern society, Yunnan culture will be faced with more serious challenges from cultural development and operation institutions from other areas.

It will be a difficult and long way for Yunnan culture in the respects of content extraction and core value refining. Yunnan culture also needs to find as many integrating points with modern "universal value" as possible to take root in South and Southeast Asia. The recent success of the premiere of ethnic dance drama "Tea-horse Ancient Road-Trace on the Ancient Road" by Yong Tan in Kunming would resurrect the tea-horse spirit and promote the cultural export by overseas shows in relevant countries [16], which gives a good example for Yunnan culture export and contributes to the B\&R development.

\section{CONCLUSIONS AND SUGGESTIONS}

As mentioned above, Yunnan culture export is still passive and responsive. In recent years, Yunnan has made remarkable achievements in the process of cultural export, but Yunnan has not been able to cultivate renowned and competitive "Yunnan cultural fashion" and leading cultural brands and enterprises throughout South and Southeast Asia. The reasons for that are: short settling time of Yunnan culture export strategies, insufficient experience, and immature core beliefs and low-end position at the cultural industrial chain, etc.[4] Many disadvantages greatly restrict the pace and efficiency of Yunnan cultural export, such as deficiencies of soft and hard power, especially the deficient positioning of self-cultural people in these countries, and there is not an international image - regional cultural spokesperson.

identity and cultivation of cultural attraction. In order to successfully export Yunnan culture, apart from the application of direct "soft conditions" including cultural output methods, means, channels and ideas, future studies would be taken in the development and coordination of indirect "fundamental conditions" such as cultural resources, human environment, policy environment, economic conditions and psychological characteristics. The value transformation and development of cultural itself should also be considered. Even if China has the economic advantages over the other Asian countries, it is not advisable to impose the consumption of Chinese cultural products through economic force [18] and dominate other culture through capital advantage, but to set up international dialogue by converging common people through international cultural cooperation or establishment of overseas Chinese culture center for example. Thus, the appreciation of different cultures will enable people to understand, trust and respect each other and live in harmony, peace and prosperity, as advocated by the Belt and Road Forum for International Cooperation [14].

\section{ACKNOWLEDGMENT}

On the completion of the paper, we would like to express deepest gratitude to all those whose kindness and advice have made this work possible. We would love to give many thanks to Professor Li Zhu in helping with the understanding of the B\&R. His effective advice, shrewd comments and constructive suggestions have paved the way for our selfdevelopment. The authors feel greatly indebted to their families who gave great support for the research of this paper. They constantly encouraged us when we felt frustrated.

\section{REFERENCES}

[1] Z. Liu, "The Regional Advantages of Yunnan Ethnic Culture for Southeastern and South Asia," Thinking, 1998, pp. 54-57.

[2] B. Dino, "Occupation of Most Markets in the World: Hollywood's Globalization in 1990's," Translated by Pang Yaping, World Movie, 2001, pp. 118-129.

[3] J. Xu, "An Analysis on Chinese Road of Culture-oriented Development," International Studies, vol. 5, 2015, p. 1.

[4] Q.L. Li and Z.Y. Li, "Reflection on Improving the International Communication Ability of Minority Culture in China," Guizhou Ethnic Studies, vol. 12, 2015, pp. 43-47.

[5] J. Yang, "Overall Promoting the Openingup of Yunnan to South Asia," Journal of Kunming University of Science and Technology, vol. 4, 2008.

[6] M. Xi, "The Strategic Dimensions for Cultural Industry Development in the Framework of the 'Belt and Road' Initiative," Renwen Tianxia, vol. 50, 2015, pp. 2-7.

[7] W.D. Liu, "Scientific understanding of the Belt and Road Initiative of China and Related Research Themes," Progress in Geography, vol. 34, pp. 538-544.

[8] X.T. Yuan, "An Analysis of the State Strategy for Building the B\&R," Theory Monthly, vol. 11, 2014, pp. 5-9.

[9] Y. Chu, and R.H. Huang, "Probe into Smart Power of National Image under the Perspective of 'One Belt and One Road'," Journal of Xinjiang 
Normal University (Philosophy and Social Sciences, vol. 2, 2016, pp. 78-84.

[10] Y. Wan, “An Overview of China's Cultural Soft Power in South Asian Countries," Managers' Journal, vol. 1,2014, p. 345.

[12] A Review of $\mathrm{De} \mathrm{La} \mathrm{Mu}$, from: http://3y.uu456.com/bp2q710c34a4s177232f60a2b2-1.html

[13] An Overview for the Opening up and Cooperation between Yunnan and South Asian countries in Recent Years, from: http://m.3y.uu456.com/mbp_5j1jz3lihg6x2111f558_1.html.

[14] Building the Belt and Road: Concept, Practice and China's Contribution, from: https://www.yidaiyilu.gov.cn/wcm.files/upload/CMSydylyw /201705/201705110537027.pdf.

[15] "Yunnan Sample" of Exported Cultural Industry, from: https://www.yndaily.com/html/2015/wenti_0802/20507.html.
[11] Yunnan Governmental Research Office, Publicity Department of Yunnan Provincial Committee of the Communist Party of China, Innovation for Ethnic Cultural Development, (Kunming: Yunnan People's Publishing House), 2001, p. 58.

[16] The Premiere of Ethnic Dance Drama "Tea-horse Ancient Road-Trace on the Ancient Road", from: http://www.yn.xinhuanet.com /newscenter/ 201706/17/c 136372687.htm.

[17] The Publication of The Plan on Reinvigoration of the Cultural Industry, from: http://www.gov.cn/jrzg/2009-09/26/content_1427394.htm.

[18] Theory of Criticism from: http://baike.baidu.com/link?url=qJKUvixb BKGhQEVKe3XS13XYLTGgRBLfr2JKVCwL5EvVB4oE035xYlorg NYbY9hVI8dVHmeMqIKU0vSfYC0IatnNEE8UDy41HEyK5ZNfei0B zfstwMQovC7WItKVzn13. 